\title{
TEXTOS ORAIS: ANÁLISE DA CONVERSA INFORMAL E ENSINO DO PORTUGUÊS LINGUA ESTRANGEIRA
}

Isabel Duarte*

Resumo: Defende-se o treino da competência de compreensão oral dos estudantes de Português Língua Estrangeira a partir de documentos orais autênticos, particularmente conversas orais reais espontâneas. Além da análise pormenorizada dos documentos e seus contextos, preconiza-se o levantamento de elementos linguísticos que permitam uma melhor compreensão dos sentidos e o reemprego adequado quando da produção de textos do mesmo género discursivo. Exemplifica-se, brevemente, um trajeto possivel com excerto de transcrição de gravação de uma conversa informal.

Palavras-chave: Conversa informal. Ensino do PLE. Competência oral.

\section{INTRODUÇÃO}

O ensino de uma língua estrangeira implica equacionar com clareza quais as finalidades que com ele queremos atingir, para que aprendam os estudantes essa língua. Como sabemos, há ensino da língua para fins específicos, isto é, com frequência, os alunos querem conhecer uma língua por motivos muito focados, práticos e pontuais. Podem aprender, e pensando agora, especificamente, no português, Português para turismo, Português para fins económicos, Português para juristas etc. Mas, para a grande generalidade dos aprendentes de uma língua estrangeira, o objetivo central da aprendizagem dessa língua é poderem comunicar através dela e com ela. Por isso, quer queiramos, quer não, isto é, quer apoiemos uma abordagem comunicativa da lingua, quer consideremos que ela tem limites e a procuremos alargar com outros ingredientes que não apenas o desenvolvimento da comunicação mais estrita, por exemplo, incentivando os alunos a conhecerem as literaturas 
dessa língua, temos de encarar a capacidade de comunicar na língua que se aprende como o principal objetivo do ensino de uma língua estrangeira. Aliás, se tivermos em conta o Quadro Europeu Comum de Referência para as Línguas (CONSELHO DA EUROPA, 2001), um documento do Conselho da Europa que regulamenta e uniformiza, na Europa, os diferentes níveis de proficiência nas várias competências que a aprendizagem de uma língua estrangeira implica, teremos de conferir um lugar de destaque à competência comunicativa, necessariamente imbricada num conjunto complexo de outras competências que a ela estão interligadas. Como diz Sonsoles Fernández (2003, p. 28, tradução nossa),

[...] o principal objetivo da aprendizagem de linguas é o desenvolvimento da competência comunicativa ou capacidade (conhecimento e uso) para interagir linguisticamente de forma adequada em diferentes situações de comunicação, tanto de forma oral e quanto escrita ${ }^{1}$.

Há, evidentemente, muitas formas e graus de conhecer uma língua. Há línguas que falamos muito bem, outras que lemos de forma competente, mas falamos mal, outras que conseguimos perceber por escrito, mas cujas produções orais não compreendemos. Podemos, ainda, saber falar uma lingua de herança, mas não conseguirmos expressar-nos, por escrito, nessa língua. Mas, quando consideramos que sabemos uma lingua estrangeira, estamos geralmente a pensar que conseguimos falar essa língua, isto é, que somos capazes de nos expressar e de comunicar, por meio dela, com outros falantes, nativos ou não, que nela igualmente se comuniquem. Esta competência não implica apenas que tenhamos capacidade para compreender discursos orais produzidos na lingua que se aprende, nem tampouco que saibamos produzir umas frases gramaticalmente corretas nessa lingua. Pressupõe, ainda, que saibamos interagir verbal e oralmente na lingua que estamos a aprender, o que não passa, apenas, por conhecermos a gramática da língua e o seu léxico, tal como pensava a pedagogia tradicional. A mudança de perspectiva que se exige para que os estudantes mobilizem o que sabem no sentido de se adaptarem, discursivamente, às situações comunicativas em que se vierem a encontrar passa pela consideração de uma pedagogia dos discursos, nas suas múltiplas vertentes e variedades. Como bem refere Olivia Figueiredo (2010, p. 172), comentando os limites dessa tradição:

A única relação que os alunos, formados neste paradigma, têm com a língua não vai para além de uma língua formulada em termos de morfossintaxe. Acabam por dominar, no geral, a morfologia e a sintaxe nas suas formulações mais clássicas e normativas, mas têm um fraco desempenho em mobilizar a língua em função das suas condições de emprego. Vão sabendo como é que funciona a língua, mas sabem muito pouco como é que a devem fazer funcionar nas situações concretas de usos; têm uma imagem representativa da língua estrangeira, mas não a aliam à sua função comunicativa; armazenam saberes, mas têm dificuldade em processar informações novas e originais a partir dos saberes interiorizados; sabem significados de palauras, mas têm dificuldade em

No original: "objetivo principal del aprendizaje de las lenguas es el desarrollo de la competencia comunicativa o capacidad (conocimiento y uso) de interactuar lingüísticamente de forma adecuada en las diferentes situaciones de comunicación, tanto de forma oral como escrita". 
estabelecer entre eles novas relações de sentidos; sabem como funciona a gramática na língua, mas não sabem como funciona a língua nos discursos; têm dificuldade em mobilizar aquilo que sabem e adaptá-lo à situação que se vive.

A nossa preocupação prende-se, portanto, com uma nova perspetiva que tenha em conta os ensinamentos da Pragmática e da Análise do Discurso, a consideração dos contextos, a relação destes com os discursos e os seus produtores, a atenção aos documentos reais produzidos por falantes da lingua, os exemplos eventualmente retirados de corpora, em vez do uso de material forjado propositadamente para os aprendentes da lingua, simplificado e artificial, limpo de dificuldades.

Neste texto, vamos focar a competência comunicativa especificamente na sua vertente oral e, dentro dela, privilegiaremos a receção em detrimento da produção, embora não nos possamos esquecer de que ambas estão entrelaçadas de forma circular: fala melhor quem está mais exposto a produtos orais variados na língua que aprende; e quem mais e melhor consegue comunicar vai-se tornando mais eficiente na receção dos vários discursos orais e na descodificação dos diferentes sentidos.

Dentro dos discursos orais aos quais propomos que sejam expostos os estudantes para treino da competência oral, iremos privilegiar, embora não exclusivamente, os que se inserem no âmbito da interação discursiva, de vários géneros textuais orais, mormente a conversa informal. Acresce que a competência comunicativa vai de par com as competências pragmática e cultural, porque todas concorrem, em conjunto, para a adequação discursiva dos discursos produzidos. No percurso de um estudante que aprende Português como língua estrangeira, deverão estar presentes, com frequência, momentos de exposição a produções orais reais em lingua portuguesa. Ou seja, para adquirirem destreza de expressão oral, os alunos devem ser expostos a um input compreensível e rico, em quantidade considerável, com registos variados e de diferentes géneros discursivos, obviamente de documentos reais. Mas, antes de chegarmos a esse ponto, para poder selecionar material que constitua o tal input rico e variado, tem o professor de possuir conhecimentos sobre as realizações orais da língua, saber que traços a caracterizam, antecipar que problemas de aprendizagem se irão colocar aos seus estudantes, que dados é fundamental eles dominarem para poderem avançar no caminho da comunicação.

Como Johnen (2012) defende, não há materiais de muita qualidade acessíveis para o treino da competência comunicativa em PLE, pelo menos a julgar pelos manuais existentes e as gravações que os acompanham. Precisa de uma revisão urgente a forma como os materiais didáticos disponiveis propõem que se ensine a compreender e a produzir textos orais, sobretudo em interação. Por concordarmos inteiramente com Thomas Johnen, pelo menos no que ao ensino do Português Europeu como Língua Estrangeira diz respeito, temos feito algum trabalho em duas direções. Por um lado, prosseguimos na constituição de um corpus de gravações e transcrições de conversas orais informais e espontâneas, para podermos estudar as respetivas caracteristicas linguístico-discursivas, muito pouco analisadas no caso do $\mathrm{PE}^{2}$. Por outro lado, enquanto docente de

2 Trata-se de um corpus de conversas informais orais recolhidas e transcritas no âmbito dos trabalhos do Centro de Linguística da Universidade do Porto, segundo as normas do grupo Va.Les.Co, da Universidade de Valência (cf. BRIZ, 2013). 
mestrandos em Português Lingua Segunda/Lingua Estrangeira ${ }^{3}$, temos insistido na importância crucial da constituição de uma gramática da comunicação oral para a formação eficaz de futuros professores de PLE. Ora, essa gramática, no caso do Português Europeu, está por fazer.

Serão objetivos deste texto, depois de procedermos a algumas reflexões iniciais: 1. defender a vantagem da audição e análise de conversas informais no ensino do Português Língua Estrangeira; 2. destacar alguns fenómenos a estudar nos documentos autênticos propostos; 3. exemplificar um percurso possivel.

Ciente de que não é possivel tratar a extensão e a complexidade de todas as vertentes que se colocam ao ensino da competência comunicativa, no sentido, sobretudo, de uma competência para agir, verbalmente, em PLE, isto é, de interagir com os outros, oralmente, em PLE, seleciono um ângulo de focagem, a saber, aquele que parte da audição e análise de conversas espontâneas previamente gravadas e posteriormente reproduzidas e transcritas, para pôr o estudante em contacto com produções reais e fenómenos atestados e não com modelos artificiais e asséticos que nada têm a ver com as trocas reais que se desenrolam entre interlocutores nativos da lingua a aprender.

\section{QUE DOCUMENTOS USAR}

Tendo em conta que deveremos colocar, desde o início, o estudante em contacto com documentos reais orais, podemos tentar começar pela escuta atenta de textos orais monogerados que não sejam muito complexos, textos de noticiários da rádio ou da televisão, onde não haja muitas marcas de coloquialidade, nem sobreposições ou hesitações em excesso. Mas, mal os aprendentes comecem a revelar alguns conhecimentos, advogamos a ideia de, ainda no nivel inicial da aprendizagem, lhes disponibilizarmos textos orais gravados que sejam conversas informais orais, primeiro apenas ouvidas, depois ouvidas ao mesmo tempo que os estudantes têm acesso à transcrição da gravação. O trabalho a realizar, depois dessa segunda audição, pode ser de vários tipos, como veremos mais adiante.

Como defende Ana María Vigara Tauste (1996), na aula de língua estrangeira deve haver espaço para o estudo da língua oral e de textos orais reais, com o objetivo primordial de promover a comunicação oral do aluno em circunstâncias reais da vida quotidiana. Quer o docente, no seu trabalho de preparação dos materiais e das sessões com os alunos, quer estes, depois, orientados pelo professor $^{4}$ terão de fazer uma reflexão sobre as diferenças entre a oralidade e a escrita, compreendendo que não são duas realidades radicalmente opostas, mas que se diferenciam de forma escalar, havendo discursos orais muito formais que se aproximam da escrita pelo seu planeamento rígido, pela sintaxe conforme às regras da norma padrão e pelo léxico vigiado, mas também há discursos escritos que se assemelham a discursos orais, por exemplo, no uso de deícticos que remetam para a situação enunciativa. Vejamos: se o locutor deixar um recado na cozinha de sua casa, dizendo "Venho tarde. Vão jantando. Deixei empadão no forno", os interlocutores (que são mais do que um - "vão") sabem quem escreveu

3 Nomeadamente na Unidade Curricular Gramática da Comunicação Oral e Escrita e na orientação e discussão de dissertações de mestrado (Mestrado em Português Língua Estrangeira / Língua Segunda, da Faculdade de Letras da Universidade do Porto).

4 Ou sozinhos, depois das aulas, em trabalho autónomo. Este tipo de esforço individual, alavancado pelas novas tecnologias, permite que o estudante esteja muito mais tempo em contacto com a língua que aprende do que tradicionalmente acontecia. 
o bilhete, o que significa, para o locutor em casua, "vir tarde", onde está o forno; sabem que o empadão que ficou no forno será para eles comerem etc. E não nos esqueçamos de que muitas formas de comunicação atuais (trocas linguísticas por SMS, Messenger, WhatsApp, nas redes sociais) estão próximas, comunicativamente, da imediate $z$ da oralidade, partilhando, pelo menos em parte, algumas das suas características. Além da reflexão sobre as diferenças entre oralidade e escrita e da problematização da distância escalar entre elas, a consideração das características do oral é necessária para os estudantes perceberem o que está em causa na sua aprendizagem, mas, sobretudo, para os professores que têm de o ensinar. Estamos, como acima ficou dito, a pensar sobretudo no oral interacional informal, quer selecionemos exemplos de textos orais autênticos dos media, quer de gravações de conversas informais.

Sabemos hoje, com dados da investigação empírica, que "os estudantes que foram sistematicamente expostos a um input autêntico de materiais de escuta tiveram melhores desempenhos do que os que foram expostos exclusivamente a dados não autênticos"5 (NUNAN, 1999, p. 210, tradução nossa). Bastaria esta conclusão para nos fazer optar por este tipo de documento. Mas, além do mais, os documentos autênticos são, geralmente, muito mais motivadores do que os que são forjados pelos autores de manuais de modo, prioritariamente, a cobrirem o estudo de certas e específicas questões gramaticais ou lexicais e é muito mais fácil recuperar o respetivo contexto comunicativo e enunciativo, opção crucial para a abordagem pragmática que propomos. Documentos reais criam maior impacto em termos afetivos, de motivação, ao nivel da empatia e do envolvimento emocional e permitem a abordagem da gramática da lingua estrangeira num contexto mais natural. No nosso caso, limitado à oralidade, os textos áudio e audiovisuais reais estimulam um processamento cerebral abrangente, que pode resultar em aprendizagens mais duradouras (MISHAN, 2005, p. 41-42).

Há um motivo suplementar para usar textos orais autênticos no desenvolvimento da competência de compreensão oral, no caso de se estar a ensinar a variante europeia (e diferentemente do que acontece se a variante a ensinar for a do Brasil), como acertadamente apontam os documentos oficiais do Ministério da Educação (2008) português, no tocante ao ensino do Português como língua não materna:

[...] contrariamente àquilo que acontece com línguas como o espanhol ou o italiano, e com o português do Brasil, o português europeu contemporâneo caracteriza-se por um enfraquecimento das vogais átonas, o que o torna, na sua modalidade oral, bastante dificil de descodificar por falantes não nativos. Uma velocidade de elocução alta acentua este fenómeno, motivando processos fonológicos como supressões, assimilações e metáteses, que afastam bastante o formato de uma palavra ou de uma sequência fónica da sua representação gráfica. Daí a necessidade de, na sala de aula, se prestar particular atenção à componente oral, em especial à compreensão.

O facto de as vogais não acentuadas em Português do Brasil serem muito mais audiveis do que no Português Europeu torna a compreensão oral da primeira variante do português referida muito mais compreensivel para um estudante

5 No original: "Students who were systematically exposed to authentic listening input outperformed those who were exposed only to nonauthentic data". 
estrangeiro do que a da segunda (cf. por exemplo, o que sobre o assunto está disponível no sítio do Instituto Camões) ${ }^{6}$. Ora, quer os diálogos dos manuais de PLE que, frequentemente, fingem imitar as trocas reais orais e são o único documento de que os estudantes dispõem para contactarem com "diálogos", quer eventuais CD com gravações de documentos não autênticos disponibilizam materiais forjados, preparados para os estudantes pelos autores dos manuais, mas simplificados e artificiais, com discursos pronunciados muito clara e explicitamente, num débito propositadamente lento e silabado, totalmente diferente do que acontece na fala quotidiana dos locutores nativos, o que só dificulta a compreensão dos aprendentes, aquando do contacto com produções reais.

\section{Alguns Percursos}

No que concerne à compreensão oral, como, aliás, a quase tudo o que se ensina ou aprende, temos de considerar uma desejável progressão na dificuldade. Acontece que está por testar o que é considerado mais ou menos dificil pelos aprendentes, como Bagão (2014) foi notando, ao longo do seu trabalho de investigação-ação, numa experiência sobre a compreensão do oral, em aulas de nivel C. Talvez seja mais acessivel o contacto com discursos pertencentes ao oral mais planeado e o contacto com discursos menos planeados deva ser posterior. Propomos um caminho que parte do mais vigiado para o menos vigiado, do mais para o menos formal, do menos para o mais coloquial. Isto porque trará óbvias dificuldades de compreensão uma conversa informal entre amigos que se interrompem, falam ao mesmo tempo, sobrepondo intervenções, usam calão, palavras truncadas ("negas" em vez de negativas, "profes" em vez de professores) e um léxico mais típico do seu grupo fechado, mais próprio da tribo do que da pólis. Em todo o caso, os alunos deverão ser expostos a ambos os tipos de documentos porque, se as gravações de discursos dos media disponibilizam, geralmente, temas mais interessantes, que incitam à discussão e motivam o debate; por outro lado, as conversas informais e familiares, se é certo que configuram temas, por vezes, sem muito interesse, contêm grande riqueza de elementos linguístico-discursivos para a aprendizagem da informalidade da conversa quotidiana.

O percurso que propomos a traços largos exige várias audições de cada documento, acompanhadas de linhas de recolha de informação, de fornecimento de dados sociolinguísticos sobre os locutores, sobre as idades e profissões, sobre a situação enunciativa concreta. Nesse primeiro momento, tratar-se-á de compreender e retirar informação do discurso ouvido. Numa fase posterior, convém ajudar os alunos a identificarem, para depois usarem, quando produzirem interações, marcas da oralidade informal espontânea (ver OLIVEIRA, 2014, embora para o espanhol).

Algumas dessas marcas, presentes, geralmente, em qualquer discurso oral mais ou menos informal, serão facilmente recenseadas pelos alunos, ao fim de duas ou três escutas atentas de um dado documento: repetições, alongamento de vogais, mudanças de rumo discursivo, palavras e frases inacabadas. São um conjunto de marcadores de planeamento local de que o locutor se serve porque está, as mais das vezes, a planear o seu discurso ao mesmo tempo que o produz,

6 Características Fonéticas do Português Europeu VS Português Brasileiro (2015). 
que antecipa a reação do interlocutor, que corrige o rumo consoante as reações deste etc. Assim, ajustando-se estrategicamente ao interlocutor, o locutor procura reformular o que diz, atenuar os seus atos diretivos e modalizar os assertivos, incluir atos expressivos que sirvam a cortesia linguística, de modo a melhor gerir a relação interlocutiva. Ora, todos estes elementos podem ser destacados em discursos reais escutados e analisados e todos eles podem também ser objeto de aprendizagem e treino explícito. Kelm (2010) refere, também, as vantagens do acesso a situações de uso real da lingua para uma aprendizagem eficaz. Segundo ele, na análise de conversas, os alunos poderiam destacar: 1. as formas usadas para iniciar e terminar a conversa; 2 . as pausas, por vezes preenchidas; 3. as hesitações; 4. as interjeições, marcadores e diversas partículas da oralidade; 5. as repetições de palavras e até de frases; 6. as correções e reformulações do dito pelo locutor ou por um interlocutor.

Já desde os níveis iniciais, mas sobretudo nos intermédios, deverá chamar-se a atenção dos estudantes para os chamados marcadores linguísticos de cortesia oral que seriam, segundo Villaça e Bentes (2008), o uso de verbos modalizadores (achar, pensar) que mitigam a força ilocutória dos atos assertivos, o recurso aos chamados disclaimers cuja função é atenuar algum eventual mal estar por parte do interlocutor, a utilização de atos de justificação e as expressões ritualizadas de cortesia, isto é, atos expressivos como saudações, cumprimentos, despedidas, pedidos de desculpa, agradecimentos etc.

Nos niveis mais avançados de aprendizagem (aqueles correspondentes ao B ou C do QECRL), sugerimos que sejam introduzidas algumas noções de variação linguística. Não apenas a que decorre do facto de o português ser uma língua pluricêntrica, isto é, de haver diferentes variedades do português em pontos geograficamente muito distantes do globo, em todos os continentes, mas também a variação que existe dentro de um mesmo país, mesmo quando se trata de um pequeno país como Portugal.

Quanto ao contacto do aprendente de PLE com diferentes variantes do português, nomeadamente o Português Europeu, o Português Brasileiro, o Português de Moçambique ou Angola, por exemplo, colocam-se problemas muito interessantes, como Stichini (2014) mostrou, a partir do ensino simultâneo das variantes portuguesa e brasileira a estudantes de iniciação, na Universidade sueca de Dalarna. O facto de a professora ter explicitamente chamado a atenção, em todas as aulas, para um aspeto em que as duas variantes diferem (isto, obviamente, para além de o conteúdo essencial de cada aula versar sobre questões da língua portuguesa que são comuns às variantes de um e do outro lado do Atlântico), parece ter esclarecido os estudantes e tê-los ajudado a diferenciarem mais eficazmente o $\mathrm{PE}$ e o $\mathrm{PB}$, em algumas áreas críticas, como a colocação dos clíticos, por exemplo. A vantagem de os alunos pelo menos contactarem com diferentes variantes do português parece estar fora de discussão, até pela abertura que tal contacto dá para as diferentes culturas e literaturas em português.

Mas concentremo-nos, agora, numa dessas variedades, no Português Europeu. Para que não fiquem com uma ideia errada da língua, pensando que ela é homogénea e imutável, para sempre congelada nos dicionários e nas gramáticas, para que a entendam como organismo vivo e múltiplo que é, os estudantes deveriam contactar com a variação diatectal ou diatópica e talvez, também, com a variação diastrática, mesmo que seja a mero título informativo. Por outro lado, quando aprendem em contexto de imersão, ou seja, quando aprendem a língua 
como língua segunda e não como língua estrangeira, num país em que ela é usada, pelos falantes, como língua materna, é provável que contactem, consoante a zona onde vivem, com uma variedade que pode ser bem diferente da norma padrão. Estou a pensar, a título de exemplo, em estudantes de mobilidade que venham estudar para o Porto e rapidamente contactarão com algumas marcas vincadas do dialeto do Norte de Portugal. Encontrarão, por certo, falantes que realizarão sempre b em vez de v, o chamado betacismo, característico do dialeto nortenho, no qual se reduz a diferença entre b e v. Devem também ouvir, permanentemente, o ditongo nasal óm/um em vez de ão, entre muitos outros fenómenos que afetarão, se para eles não estiverem devidamente alertados, a compreensão dos discursos quotidianos que manterão com os locutores nativos.

Além dos fenómenos prototípicos de certos falares regionais, há características próprias do discurso oral espontâneo em português que, se não forem identificadas, tornarão irreconheciveis, na compreensão oral, palavras que os estudantes podem conhecer da escrita ou do oral forjado típico dos materiais mais caracteristicamente escolares. Refiro, por exemplo, a síncope da primeira sílaba da palavra ("que "tive a ver", em vez de "estive"; "Olha "tás a ensinar-me", em vez de "estás"), "Prá "prender pa fazer" em vez de "para aprender para fazer", "pera aî", em vez de "espera aî"); ou o chamado encontro de palavras (como em "gosta dalmoçar" em vez de "gosta de almoçar"); ou fenómenos de alteração da forma como a palavra se pronuncia na norma (como "tamém", em vez de "também"), por exemplo.

Antes mesmo de se proceder a meras tarefas de compreensão dos diferentes documentos orais, pelo preenchimento de espaços, exercícios de escolha múltipla, quizz, exercícios posteriores à escuta etc., convém fornecer aos estudantes uma ficha completa dos dados que identifiquem o máximo dos parâmetros em causa na situação enunciativa de que decorre o discurso oral em análise, para que os alunos possam estabelecer as necessárias relações entre o produto verbal oral e os respetivos produtores e condições de produção. Anexamos, a este respeito, um exemplo de uma ficha de recolha de dados de gravação, a discutir com os alunos aquando da apresentação do documento oral e respetiva transcrição (ver Anexo $\mathrm{I}^{7}$ ). Isto porque não é possivel estudar um discurso sem conhecer as suas circunstâncias e porque, como diz Lopes (2011, p. 228), o conhecimento gramatical "será tanto mais efetivo quanto mais se acentuar a vinculação da língua (enquanto sistema gramatical) às práticas sociais e à interlocução". Ou seja, para os estudantes conhecerem o sistema gramatical da lingua que aprendem, com segurança, dever-se-á relacionar a língua com o discurso, com a sua vocação interativa.

A análise atenta da ficha precederia a audição da gravação, a partir da qual estudantes e professor deveriam realizar um levantamento de especificidades do oral, como acima já escrevemos. A distinção de diferentes tipos de discurso oral também é um exercício útil, porque cada género discursivo tem as suas regras e constrangimentos próprios que os alunos devem conhecer, até para poderem, posteriormente, produzir discursos dos géneros em causa (entrevista, debate, conversa, exposição formal etc.).

O estudo e treino de marcas linguístico-pragmáticas típicas da comunicação imediata, espontânea e coproduzida por interlocutores implicados (marcadores

7 Tanto a Ficha sociolinguística como as normas de transcrição são adotadas do grupo Va.Les.Co da Universidade de Valência (BRIZ, 2013) e usadas, por nós, no projeto Es.Por.Atenuación. 
discursivos conversacionais, relato do discurso na narração oral, formas de imprecisão e de vago, formas de tratamento ${ }^{8}$, fórmulas rituais etc.) são momentos fundamentais deste percurso, como exemplificaremos, rapidamente, a seguir.

\section{EXEMPLIFICAÇÃo BREVE}

Nesta breve exemplificação, confrontaremos um diálogo extraído de um manual de PLE Português com excertos de uma conversa real entre dois interlocutores (aquela cuja ficha de identificação está no Anexo). Procuraremos chamar a atenção, no excerto da conversa real, para aspetos que crucialmente a constituem.

Documento 1 (OLIVEIRA; COELHO, 2007, p. 47):

\section{Diálogo 1}

Sara: Luís, achas que eu estou bonita como este penteado?

Luís: Não. Eu não gosto desse corte de cabelo.

Sara: Se não gostas do meu cabelo é porque não tens bom gosto.

\section{Diálogo 3}

Maria: Ontem fiz uma festa na minha casa.

João e Rita: Porque é que nós não fomos convidados?

Maria: Porque era uma festa apenas para a minha família.

João e Rita: Nós não ficamos zangados.

\section{Diálogo 2}

Ana: Rui, amanhã vou chegar mais tarde a casa.

Rui: A que horas vais chegar?

Ana: Eu vou chegar depois do jantar.

Rui: Então, eu vou jantar fora com os meus amigos.

\section{Diálogo 4}

Manuel: Na semana passada telefonei para a tua casa, mas não atendeste o telefone.

Sandra: Na semana passada eu estive no Porto.

Manuel: O que é que fostes fazer ao Porto?

Sandra: Fui visitar uns amigos que moram lá.

O Documento 1 merece um comentário breve. São quatro diálogos que o manual pede para o estudante passar para o discurso indireto. Não vou discorrer sobre a validade deste exercício e até sobre a aceitabilidade das frases dele resultantes, gramaticalmente falando (DUARTE, 2003; MONTEIRO, 2014). Noto apenas a artificialidade extrema dos textos: ninguém fala assim. No diálogo 1, é pouco provável que Luís respondesse como no texto, sem qualquer atenuação, usando o pronome "eu" (o pronome sujeito é muito menos utilizado em PE do que em PB). A resposta da Sara nunca teria tanta informação. Seria, presumivelmente, algo como "Se não gostas, não tens bom gosto", e nunca seria tão redundante: "Se não gostas do meu cabelo é porque não tens bom gosto". Na conversa oral, porque partilhamos a situação enunciativa e o conhecimento do mundo, não precisamos de explicitar todas as informações. Igual comentário se poderia fazer a propósito dos restantes diálogos. No segundo, Rui responderia, talvez, à primeira intervenção da Ana, dizendo "A que horas?” e nunca "A que horas vais chegar?". E ela dir-lhe-ia "depois do jantar" e nunca "Eu vou chegar

8 Não é possível referir, numa nota, todos os trabalhos de Maria Helena Carreira sobre as formas de tratamento em PE, nem tampouco relatórios de mestrado que têm sido realizados na Faculdade de Letras da Universidade do Porto sobre as temáticas referidas acima. Mas destacaria Carreira (2008), sobre formas de tratamento; Duarte e Silva (2011), Silva e Duarte (2012) e Marques (2014b) para o relato de discurso e as seguintes dissertações de mestrado: Monteiro (2014), Gomes (2013), Alves (2013) e Oliveira (2014) para o relato de discurso, a atenuação e os marcadores conversacionais. 
depois do jantar". No diálogo 4, nenhum falante diria, como Manuel, "não atendeste o telefone", mas apenas "não atendeste", porque o objeto direto é demasiado óbvio para ter de ser explicitado. E a última réplica deste diálogo seria "Visitar uns amigos" e nunca "Fui visitar uns amigos que moram lá". Poderíamos fazer, com os estudantes de PLE, o exercício de identificar os elementos dos textos que estão claramente a mais, isto é, que não seriam produzidos num diálogo real, por não serem necessários para a coconstrução do sentido pelos interlocutores.

\section{Documento 2:}

1. B: $\uparrow$ ela a mim dizia-me uma bez eu bi lá umas botas que gostei muito e ela disse entra Fatinha// ai eu posso entrar mas nem penses [que]

2. A: [(RISOS)]

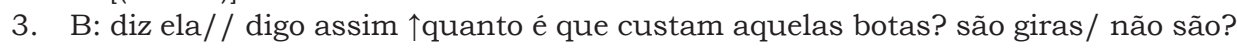
$\downarrow$ digo assim são/ duzentos e não sei- oh oh// Carminho/ por amor de Deus// eu não sou rica

4. A: (RISOS)

5. B: diz ela assim/ ah mas tu podes pagar em duas ou três bezes/ não Carminho/ não/ nem pensar/ não quero $\downarrow$ [obrigada]/ [mesmo] pagando em duas e três [vezes] [não] Carminho/ não/ nem pensar/ não quero $\downarrow$ [obrigada]

6. A: [mesmo] pagando em duas e três [vezes]

7. B: [não]

8. A: =não deixa de ser [um total]

9. B: [não não]

10. A: =não deixa de ser duzentos

11. B: não não/ Carminho

12. A: (RISOS)

13. B: isso é p(ara)os teus clientes/ tu é que tens aqui clientes muito ricos/ eu não sou rica [e ela]

14. A: $[\operatorname{sim}] /$ mas pronto era- era- era- era o- era o negócio dela

$15 \mathrm{~B}: \operatorname{sim} / \operatorname{sim}$.

Vejamos alguns aspetos a comentar, nesse excerto de conversa entre mãe e filho. Dentro da narração de um pequeno episódio, a mãe reproduz, para o filho, um diálogo que tinha tido, tempos antes, com alguém que acaba de falecer e trabalhava uma sapataria cara da cidade.

$\mathrm{Na}$ linha 1, em "ela a mim dizia-me uma bez eu bi lá umas botas que gostei muito", temos a assinalar os seguintes fenómenos: mudança de rumo discursivo, já que o locutor inicia a réplica por "ela a mim dizia-me" e interrompe a frase, deixando-a sem objeto direto, para contar um episódio "uma bez bi lá umas botas que gostei muito". Já falámos do betacismo típico do dialeto nortenho, marca do falante B durante toda a conversa: "bez", "bi", em vez de "vez", "vi" etc. A relativa cortadora ("umas botas que gostei muito" em vez de "umas botas de que gostei muito") é também característica da oralidade. Quando B reproduz o diálogo que manteve com a vendedora, temos, num primeiro momento, uma introdução de discurso direto canónica: "e ela disse". As palavras da interlocutora de então são, obviamente, palavras imaginadas no presente e atribuídas a essa interlocutora, entretanto falecida e que não podiam ter sido memorizadas tal e qual. São ficção para tornar a narração do episódio mais viva: "entra Fatinha//". O ato diretivo de convite, na segunda pessoa do singular do imperativo, 
bem como o diminutivo no nome próprio revelam proximidade entre os interlocutores. Mas, quando B reproduz a sua resposta, "ai eu posso entrar mas nem penses [que]", já não há qualquer introdução narrativa e a réplica segue-se à da interlocutora sem transição. A interjeição "ai", no início de um turno de fala, é apenas um elemento conversacional que sugere que o que vai ser dito conflitua, em algum grau, com o que foi produzido pelo interlocutor, ou reforça o carácter adversativo do que se lhe segue, como é o caso: "eu posso entrar mas nem penses [que]". Isto é, B adverte logo a vendedora de que, mesmo entrando na loja, não irá comprar nada.

Em 2, os risos do interlocutor A abafam o início da intervenção de B ("diz ela" parece mostrar que algumas palavras, reproduzidas posteriormente, não se ouviram), que prossegue o relato do episódio. O diálogo com a vendedora continua a ser relatado por $\mathrm{B}$, com sequências introdutoras do discurso direto, curiosamente, como frequentemente acontece na oralidade, com o verbo "dizer" não no pretérito perfeito, como seria de esperar e vimos anteriormente ("disse ela"), mas no presente do indicativo, um presente semelhante ao chamado presente histórico, que procura tornar mais viva a narração, por mais próxima do ato enunciativo: “digo assim $\uparrow$ quanto é que custam aquelas botas?”. À pergunta de B, a vendedora responde "são giras/não são?", procurando, através dos elementos destacados a negrito, uma confirmação da interlocutora, a sua concordância com o ato expressivo de apreciação. Essa confirmação chega, como previsto: "digo assim são". E a vendedora responde, finalmente, à pergunta de B, resposta adiada pelo comentário sobre a beleza das botas e o pedido de confirmação da opinião: "duzentos e não sei-". Contrariamente ao diálogo real que a narrativa oral procura reproduzir, a vendedora deve ter dito o preço exato das botas em euros. A expressão de vago ou imprecisão "duzentos e não sei-" usa-se porque é irrelevante do ponto de vista argumentativo, na enunciação relatora, que as botas custem duzentos e trinta ou duzentos e setenta, uma vez que, para a eventual compradora, seriam sempre excessivamente caras (DUARTE; CARVALHO, no prelo). Por isso B terá interrompido a vendedora, por meio de um ato expressivo de rejeição do conteúdo proposicional da intervenção anterior, isto é, da informação sobre o preço excessivo das botas: "oh oh// Carminho/ por amor de Deus / / eu não sou rica”. O ato expressivo correspondente ao espanto perante o preço está marcado pela dupla interjeição inicial e pela expressão exclamativa "por amor de Deus" que, como Liana Pop (2012, p. 91) assinalou para o romeno, tem um funcionamento de intensificador, no seu grau máximo. A face do outro não é, no entanto, ameaçada, porque B usa o diminutivo para se dirigir ao interlocutor - "Carminho" -, e porque apresenta, como é habitual nessas situações, uma justificação, com função de atenuador, para não comprar as botas e para se manifestar de forma tão veemente: “eu não sou rica”. No jogo argumentativo que faz parte da venda, Carminho insiste, com um argumento que tenta persuadir a sua interlocutora: "diz ela assim/ ah mas tu podes pagar em duas ou três bezes /". "Diz ela assim" é um introdutor muito frequente do discurso oral relatado (DUARTE; SILVA, 2011; SILVA; DUARTE, 2012; MARQUES, 2014b; MONTEIRO, 2014). Quanto à interjeição, já vimos que papel desempenha, as mais das vezes, no início de uma réplica: reforça a concessiva, ou seja, neste caso, sublinha um argumento por meio do qual o locutor tenta convencer o alocutário. A recusa frontal do negócio proposto está plasmada pelos turnos seguintes 
de B e também pela concordância de A: "não Carminho/ não/ nem pensar/ não quero $\downarrow$ [obrigada] [mesmo] pagando em duas e três [vezes] [não] Carminho/ não/ nem pensar/ não quero $\downarrow$ [obrigada]". As repetições não são, neste caso, sinal da pressão da planificação discursiva que se realiza ao mesmo tempo que se fala, não são sinal de hesitação, mas antes marca de intensificação. A sintonia de A e B pode verificar-se pela forma como as respetivas réplicas se repetem e completam: A afirma, em três sequências interrompidas por B, o seguinte: "[mesmo] pagando em duas e três [vezes]" (interrupção de B, que continua a repetir que não quer o negócio: [não]) + "=não deixa de ser [um total]" (nova interrupção de B: [não não]) + “=não deixa de ser duzentos". Ou seja, A diz o seguinte: "Mesmo pagando em duas e três vezes, não deixa de ser um total, não deixa de ser duzentos", reforçando a sua concordância com os argumentos da mãe, que não se deixa persuadir, pela vendedora, a comprar as botas. B continua, várias réplicas abaixo, o relato do diálogo que mantivera com a vendedora ("não não/ Carminho"), sublinhando a veemência da recusa e a concordância com a posição sensata do filho, que ri. E a réplica relatada continua depois, num bom exemplo daquilo a que Slama-Cazacu (1982) chamou "sintaxe dialogal", ou seja, enunciados que se vão completando em diferentes turnos de fala (POP, 2012, p. 86): “isso é p(ara)os teus clientes/ tu é que tens aqui clientes muito ricos / eu não sou rica [e ela]". A continuação da narração do episódio é cortada por A, que justifica a atitude da vendedora (“[sim]/ mas pronto era- era- era- era o- era o negócio dela”), mostrando que, apesar de tudo, não vale a pena discutir porque "era o negócio dela", ideia com que A concorda: "sim/ sim". O valor pragmático de "pronto" merece também referência, como a seu tempo mostraram Silva (2002), Christiano e Hora (1998) e Marques (2014a).

Este excerto de conversa entre A e B, em que B narra a A um pequeno episódio passado entre si e a jovem de cujo funeral estão a falar, conta, portanto, com sequências dialogais relatadas, dentro da narração do episódio. Será um bom exemplo de contacto, para estudantes de PLE, com a comunicação imediata, espontânea e coproduzida por interlocutores implicados. O seu confronto com os "diálogos" do Documento 1 é fundamental para o percurso por nós previsto. Permitir-nos-ia, depois de realizado um estudo que relevasse os fenómenos anteriormente sublinhados, propor aos estudantes um conjunto de tarefas.

Em primeiro lugar, poderiam tentar transformar a narração oral do episódio numa pequena narração escrita, em que existisse uma sequência dialogal, com as convenções gráficas e de pontuação que implica.

Depois, poder-se-ia estudar a troca comercial como género discursivo e os estudantes poderiam produzir, em role playing, interações típicas de diferentes estabelecimentos comerciais. Este exercício oferece amplas possibilidades de variar os parâmetros, o tipo de compra, os atos diretivos de pedido (outras cores, outros tamanhos, outros preços menos caros do produto que se vai comprar), os atos expressivos (gostos, apreciação dos artigos), elementos de atenuação, atos indiretos (a vendedora que aconselha outro produto que fique melhor à cliente do que o que ela quer comprar) dependentes da cortesia linguística, atos rituais de cumprimentos, despedidas, agradecimentos etc. Esta abordagem dá mais sentido ao estudo do léxico (por exemplo, neste caso, da compra e venda, do comércio de sapataria etc.) do que se os alunos decorarem longas listas de palavras fora de qualquer contexto (FIGUEIREDO; FIGUEIREDO, 2010). 


\section{ConClusão}

A forma mais proveitosa de ensinar uma língua estrangeira é pelo contacto permanente do aluno com discursos variados realmente produzidos nessa língua. Quando pretendemos melhorar a competência de compreensão e de interação oral dos aprendentes, temos de os colocar perante conversas espontâneas reais, posteriormente estudadas e analisadas tendo em conta o respetivo contexto enunciativo. Pretendeu-se mostrar que os documentos dos manuais são geralmente artificiais e muito afastados das produções reais, o que em nada ajuda os estudantes a mobilizarem os conhecimentos gramaticais e lexicais quando tiverem de entravar conversas orais espontâneas em português. As sugestões breves apresentadas são meros exemplos de todo um trabalho que está por fazer, para o Português Europeu e que se espera que venha a ter seguimento.

\section{ORAL TEXTS: ANALYSIS OF INFORMAL CONVERSATION AND THE TEACHING OF Portuguese as a Foreign language}

Abstract: We advocate the training of listening comprehension of students of Portuguese as a Foreign Language, using authentic oral documents, particularly real spontaneous oral conversations. In addition to the detailed analysis of this kind of document and their contexts, we anticipate the finding of linguistic elements that allow a better understanding of the meaning and a correct use of said elements during the production of the same kind of discursive texts. This is exemplified, though briefly, with excerpt from a recording transcription of an informal conversation.

Keywords: Informal conversation. Teaching Portuguese as a foreign language. Oral competence.

\section{REFERÊNCIAS}

ALVES, A. Os marcadores conversacionais no ensino de Português Lingua Estrangeira: um estudo de caso. 2013. Dissertação (Mestrado em Português Língua segunda/Lingua estrangeira)-Universidade do Porto, Porto, 2013. Disponível em: <http://repositorio-aberto.up.pt/handle/10216/66474>. Acesso em: 23 jan. 2015.

BAGÃO, M. T. Compreensão do oral em aulas de PLE. Contributos para atividades no nivel C. 2014. Dissertação (Mestrado em Português Língua segunda/ Lingua estrangeira)-Universidade do Porto, Porto, 2014. Disponivel em: <http:// repositorio-aberto.up.pt/bitstream/10216/77491/2/105932.pdf >. Acesso em: 12 jan. 2015.

BRIZ, A. A atenuação e os atenuadores: estratégias e táticas. Linha d’Água, v. 26, n. 2, p. 281-314, 2013.

CARACTERÍSTICAS FONÉTICAS do Português Europeu VS Português Brasileiro. Disponivel em: <http://cvc.instituto-camoes.pt/cpp/acessibilidade/capitulo4_1. html>. Acesso em: 24 de jan. 2015.

CARREIRA, M. H. (Org.). Mignonne, allons voir si la rose...: termes d'adresse et modalités énonciatives dans les langues romanes. Paris: Université Paris 8, Vincennes-Saint Denis, 2008. 
CHRISTIANO, M. E.; HORA, D. O item lexical pronto: marcador discursivo e interativo. Revista Graphos, v. 1, n. 3, p. 197-205, 1998. Disponivel em: <http:// periodicos.ufpb.br/ojs/index.php/graphos/article/view/9411/5066>. Acesso em: 2 set. 2013.

CONSELHO DA EUROPA. Quadro Europeu Comum de Referência para as Línguas. Aprendizagem, ensino, avaliação. Porto: Edições Asa, 2001.

DUARTE, I. O relato de discurso na ficção narrativa. Contributos para a análise da construção polifónica de Os Maias de Eça de Queirós. Lisboa: Fundação Calouste Gulbenkian, 2003.

DUARTE, I.; CARVALHO, A. Discours rapporté dans l'oral informel: 1'imprécision. In: BERRENDONNER, A.; HANSEN, M.-B. M.; ZAFIU, R. (Org.). Actes du XXVII Congrès international de linguistique et de philologie romanes (Nancy, 15-20 juillet 2013). Section 10: Linguistique textuelle et analyse du discours. Nancy (no prelo).

DUARTE, I. M.; SILVA, F. Revisitação do discurso relatado no ensino-aprendizagem do PLE. Comunicação apresentada no Congresso Alemão de Lusitanistas na secção À descoberta de culturas em quatro continentes através da língua: Português como Língua Estrangeira (14 - 17 setembro 2011), Universidade de Viena, Áustria, 2011.

FIGUEIREDO, O. A lingua como acto e como atitude. Da competência comunicativa às convenções culturais. Limite, n. 4, p. 167-180, 2010.

FIGUEIREDO, O.; FIGUEIREDO, E. Unidades fraseológicas no ensino de PLE. Perspectiva intercultural. Limite, n. 4, p. 155-166, 2010.

GOMES, C. Mecanismos de atenuação e intensificação no ensino do Português/ Lingua Estrangeira: um estudo de caso. 2013. Dissertação (Mestrado em Português Língua segunda/Língua estrangeira)-Universidade do Porto, Porto, 2013. Disponivel em: <http://repositorio-aberto.up.pt/handle/10216/72523>. Acesso em: 25 nov. 2014.

JOHNEN, T. La représentation écrite de l'oral dans des méthodes de Portugais Langue Étrangère. In: CARREIRA, M. H. (Org.). Les rapports entre l'oral et l'écrit dans les langues romanes. Paris: Université Paris 8, Vincennes, Saint Denis, 2012. p. 307-328.

KELM, O. Innovative Technologies - New Opportunities in Language Teaching. Portuguese Language Journal, v. 4, Fall 2010. Disponivel em: <http://www. ensinoportugues.org/archives/archived-articles-5/>. Acesso em: 28 nov. 2014.

LOPES, A. C. Actos de fala e ensino do Português como língua maternal: algumas reflexões. In: DUARTE, I. M.; FIGUEIREDO, O. (Org.). Português, língua e ensino. Porto: Universidade do Porto, 2011. p. 223-246.

MARQUES, M. A. Linguagem coloquial e modalização. Redis: Revista de Estudos do Discurso, n. 3, p. 94-106, 2014a. Disponivel em: <http://ler.letras.up.pt/ uploads/ficheiros/12964.pdf>. Acesso em: 14 jan. 2015.

MARQUES, M. A. Oralidade, coloquialidade e relato de discurso - questões de linguagem em uso e ensino do PLnM. Comunicação apresentada às IV Jornadas de Língua Portuguesa e Culturas Lusófonas da Europa Central e de Lesta, realizadas na Universidade Carolin, em Praga, 26 e 27 de setembro de 2014b. 
MINISTÉRIO DA EDUCAÇÃO. Orientações Programáticas de Português Lingua Não Materna (PLNM). 2008. Disponível em: <http://dge.mec.pt/metascurriculares/ index.php?s=directorio\&pid=53>. Acesso em: 13 jan. 2015.

MISHAN, F. Designing authenticity into language learning materials. Bristol: Intellect Books, 2005.

MONTEIRO, N. O relato de Discurso no Ensino do PLE: um caso em estudo. 2014. Dissertação (Mestrado em Português Língua segunda/Língua estrangeira)-Universidade do Porto, Porto, 2014. Disponivel em: <https://sigarra.up.pt/flup/ pt/publs_pesquisa.FormView?p_id=101682>. Acesso em: 18 jan. 2015.

NUNAN, D. Second language teaching and learning. Boston: Heinle and Heinle Publishers, 1999.

OLIVEIRA, P. Os marcadores do discurso e a didática da oralidade no ensino do espanhol como língua estrangeira. 2014. Dissertação (Mestrado em Ensino do Português no $3^{\circ}$ ciclo do Ensino Básico e no Ensino Secundário e de Língua Estrangeira nos Ensinos Básico e Secundário)-Universidade do Porto, Porto, 2014. Disponivel em: <http://sigarra.up.pt/flup/pt/publs_pesquisa.FormView? p_id=104907>. Acesso em: 12 dez. 2014.

OLIVEIRA, C.; COELHO, L. Gramática aplicada-PLE. Lisboa: Texto Editora, 2007. POP, L. De l'oral à l'écrit: articulation micro et macro-syntaxique. In: CARREIRA, M. H. (Org.). Les rapports entre l'oral et l'écrit dans les langues romanes. Paris: Université Paris 8, Vincennes, Saint Denis, 2012. p. 75-93.

SILVA, A. S. Da semântica cognitiva à pragmática lexical: polissemia da palavra pronto. In: DUARTE, I. M. et al. (Org.). Actas do Encontro comemorativo dos 25 anos do Centro de Linguística da Universidade do Porto. Porto: CLUP, 2002. p. 83-97.

SILVA, F.; DUARTE, I. M. Ainda o discurso relatado: algumas propostas de aplicação ao ensino-aprendizagem do português lingua estrangeira. Comunicação apresentada nas Jornadas Pedagógicas de Português de Estocolmo 2012 Aprendizagem e Ensino de Português Língua Estrangeira e Português Língua Materna fora do espaço lusófono: convergências e divergências (5-7 dezembro 2012). Universidade de Estocolmo, Suécia, 2012.

SLAMA-CAZACU, T. Structura dialogului. Despre sintaxa dialogată. Studii şi cercetări lingvistice, v. 33, n. 3, 4, p. 211-224, 301-321, 1982.

SONSOLES FERNÁNDEZ, M. Propuesta curricular y marco común europeo de referencia: desarrollo por tareas. Madrid: Editorial Edinumen, 2003.

STICHINI, C. Aquisição dos clíticos no ensino simultâneo de PE e PB a alunos universitários na Suécia. 2014. Dissertação (Mestrado em Português Língua segunda/Lingua estrangeira)-Universidade do Porto, Porto, 2014.

VIGARA TAUSTE, A. M. Español coloquial: expresión del sentido por aproximación. In: KOTSCHI, T.; OESTERREICHER, W.; ZIMMERMANN, K. (Org.). El español hablado y la cultura oral en España e Hispanoamérica. Frankfurt: Vervuert, 1996. p. 15-44.

VILLAÇA, I.; BENTES, A. Aspectos da cortesia na interação face a face. In: PRETI, D. (Org.). Cortesia verbal. São Paulo: Humanitas, 2008. p. 19-48. 


\section{Anexo 1}

Gravação número 1

a) Investigador: António Rafael da Silva Fernandes de Freitas

Sexo: Masculino

Idade: 25 anos

Nacionalidade: Portuguesa

Naturalidade: Guimarães

Habilitações literárias: Mestrado

b) Dados da gravação:

Gravador: Philips Voice Tracer LFH0602

Formato do ficheiro: MP3

Tamanho do ficheiro: $14,4 \mathrm{MB}$

Data: 07/12/2014

Local: Casa (quarto)

Duração: 31 minutos e 30 segundos

Observações: -

c) Dados da transcrição:

Formato do ficheiro: PDF

Tamanho do ficheiro: $339 \mathrm{~KB}$

Número de páginas: 23

Número de linhas: 737

d) Situação comunicativa:

Tema(s): O funeral de um conhecido; uma possivel prenda de Natal; o desconto feito a umas botas

Características da interação: Oral, presencial

Registo(s) de língua: Informal

e) Tipo de discurso registado: Conversação

f) Técnica de gravação: Conversação livre, gravação não secreta

g) Descrição dos participantes: 2

Número: 2

Legenda: A, B

Ativos: A, B

Passivos:- 
Tipo de relação que os une: Parentesco (A: Filho B: Mãe)

Sexo: A: masculino; B: feminino

Local de nascimento: A, B - Guimarães

Data de nascimento: A: 28/02/1989; B: 08/05/1966

Idade: A: 25 anos (<25); B: 48 anos (26-55)

Nivel de instrução:

Analfabeto

Ensino primário

Ensino secundário: B

Ensino superior: A

Profissão: A: Professor de Português Lingua Estrangeira; B: Assistente num consultório de medicina dentária

Residência: A, B - Guimarães

Nivel sociocultural:

Alto

Médio: A, B

Baixo

Local de nascimento do pai: A - Guimarães; B: Guimarães

Local de nascimento da mãe: A - Guimarães; B: Guimarães

Lingua habitual: Português Europeu (monolingue)

h) Grau de prototipicidade coloquial: coloquial prototipico

Recebido em dezembro de 2014.

Aprovado em fevereiro de 2015. 